\title{
ANÁLISE DA PRODUÇÃO DE SENTIDOS EM NARRATIVAS DE AFÁSICOS PARTICIPANTES DE GRUPO DE CONVIVÊNCIA
}

\author{
Analyzing sense production in narratives \\ for aphasic participants of the conviviality group
}

\author{
Aluísia Guerra Albuquerque (1), Maria Lúcia Gurgel da Costa ${ }^{(2)}$, \\ Ester Feijó Correia de Sena ${ }^{(3)}$, Lívia Maria da Silva Luz ${ }^{(4)}$
}

\begin{abstract}
RESUMO
Objetivo: analisar os sentidos discursivos observados na fala de afásicos participantes de um grupo de convivência. Métodos: o estudo foi realizado no Departamento de Fonoaudiologia da Universidade Federal de Pernambuco, onde foi formado o grupo de convivência de afásicos, constituído de seis sujeitos afásicos e cinco não-afásicos. Para o desenvolvimento das atividades do estudo, os encontros foram gravados e posteriormente transcritos, seguindo o sistema padronizado do NURC (Norma Universal de Transcrição), e em seguida realizada a análise. Resultados: através das transcrições, foi possível encontrar os temas comuns e recorrentes ao discurso de afásicos, foram eles: incapacidades; lembranças e conhecimentos; memórias e épocas da vida; família; religião; trabalho e doenças/acidente vascular cerebral. Os temas de maior prevalência e iniciados pelos afásicos foram sobre as incapacidades, doenças e causas do acidente vascular cerebral, principalmente as alterações linguísticas. Verificou-se que o discurso desses sujeitos, independentemente das alterações que apresentaram, está impregnado de sentidos verdadeiros, que se produzem em decorrência da interação social entre os interlocutores, sujeitos ativos nessa troca de informações e constituídos de ideologia e história. Conclusão: pode-se observar que, mesmo possuindo um discurso reduzido, os afásicos apresentaram comportamentos e tentativas de interação com o outro, estabelecendo processos de significação.
\end{abstract}

DESCRITORES: Afasia; Fala; Linguagem

\section{INTRODUÇÃO}

As doenças do aparelho circulatório são desencadeantes de transtornos cerebrovasculares, entre eles a afasia, considerada como uma perturbação da linguagem em que há alteração dos processos linguísticos, tanto do aspecto produtivo, quanto interpretativo da linguagem, causada por lesão adquirida no Sistema Nervoso Central devido a acidentes vasculares cerebrais (AVC's), a traumatismos crânioencefálicos (TCE's) ou tumores ${ }^{1}$.

\footnotetext{
(1) Fonoaudióloga.

(2) Fonoaudióloga; Docente da Universidade Federal de Pernambuco, UFPE, Recife, PE; Doutora em Educação pela Universidade de São Paulo.

(3) Fonoaudióloga da Prefeitura Municipal de Bom Jardim, PE.

(4) Aluna do Curso de Graduação em Fonoaudiologia da Universidade Federal de Pernambuco, UFPE, Recife, PE.

Conflito de interesses: inexistente
}

Os estudos tradicionais reduzem a afasia a mero problema de codificação e decodificação da língua. Quando tratada sob uma concepção discursiva da linguagem, toma necessariamente um caminho diferente dos até então realizados.

As propostas consideradas localizacionistas, encontrando-se mais fortemente atreladas ao discurso organicista, defendiam a posição de compreender a afasia a partir da ideia de que uma determinada perturbação da linguagem estaria correspondendo a uma área lesada, assim como o local da lesão poderia determinar a forma de alteração no funcionamento da linguagem ${ }^{2}$.

A concepção discursiva da linguagem é tomada como um processo de interação do qual participam interlocutores que, assumindo a posição de sujeitos, agem no e sobre o mundo através de interações verbais, usando a linguagem para influenciar o outro e ser por ele influenciado, em uma construção conjunta de sentido ${ }^{3}$. 
A Análise do Discurso (AD) fundamenta, teoricamente, a preocupação com as condições ideológicas, culturais e afetivas dos sujeitos, no momento em que produzem linguagem, mesmo diante de uma linguagem patológica. Inaugura-se, assim, uma nova perspectiva de compreensão teórica e mesmo de intervenção diante de quadros afásicos ${ }^{4}$.

O processo de Análise Discursiva tem a pretensão de interrogar os sentidos estabelecidos em diversas formas de produção, que podem ser verbais e não verbais, bastando que sua materialidade produza sentidos para interpretação. Esta está sempre passível de equívoco, pois embora a interpretação pareça ser clara, na realidade existem muitas e diferentes definições, sendo que os sentidos não são tão evidentes como parecem ser ${ }^{5}$.

Há dificuldades específicas impostas pela afasia que às vezes impedem ou tornam muito mais lentas, mais árduas, as operações sobre os recursos linguísticos - dificuldades na produção dos gestos articulatórios, dificuldades com o acesso lexical, com a estruturação sintática - que caracterizam as afasias anteriores, e dificuldades linguísticas e/ou linguístico-cognitivas que caracterizam as afasias posteriores - a relação com o outro, a adesão ao tópico discursivo - que interferem no movimento de produção dos discursos. A determinação do sentido, dessa forma, depende mais do outro, do coprocessamento realizado com os interlocutores de flechar itens do contexto ${ }^{6}$.

Não é rara a desvalorização do repertório linguístico dos sujeitos afásicos, em que se constata a cada produção a afecção que os acometeu. Assim, se as formas que constituem a fala dos sujeitos afásicos não são reconhecidas por esses autores, também não é reconhecida a manutenção da linguagem na afasia, sendo, portanto, desconsiderada como elemento presente, estruturador e permeador das relações dos sujeitos afásicos (assim como o é para os sujeitos não-afásicos) com o mundo ${ }^{7}$.

A Análise do Discurso valoriza o modo de funcionamento linguístico textual dos discursos, as diferentes modalidades do exercício da língua em um determinado contexto social e histórico que, de certa forma, interferem na produção dos discursos ${ }^{8}$.

Esse estudo torna-se necessário para a busca de estratégias que facilitem a interpretação dos sentidos discursivos dos afásicos, sendo fundamental para compreensão da dinâmica, forma e funcionamento da sua linguagem.

O estudo teve como objetivo analisar os sentidos presentes nos discursos de afásicos participantes de um grupo de convivência, relacionando-os com os aspectos ideológicos, sociais, econômicos e bio-psíquicos presentes na fala desses sujeitos.

\section{MÉTODOS}

Tratou-se de uma pesquisa qualitativa, observacional, longitudinal, descritiva, interpretativa. $O$ estudo foi realizado no Departamento de Fonoaudiologia de uma Universidade Federal do Nordeste, onde foi formado o grupo de convivência de afásicos, para o desenvolvimento das atividades da pesquisa. O encontro com o grupo ocorria semanalmente, tendo a duração de uma hora e meia.

As atividades realizadas, inicialmente, no grupo foram divididas em três momentos: o primeiro em que se realizava uma conversa espontânea sobre o que havia ocorrido durante a semana; novidades para contar; comentavam-se sobre notícias do jornal, fatos ocorridos na semana; programas da televisão, novelas, filmes, discussão sobre as afasias, suas causas e consequências linguísticas, como também os comprometimentos socioeconômicos e culturais; entre outros assuntos de interesse.

No segundo momento, eram realizadas atividades com objetivos mais específicos a fim de melhorar o funcionamento da linguagem oral. Além de atividades que envolviam a memória, foram feitas as seguintes atividades: adivinhações; dramatizações; discussão de filmes; canto e interpretação de músicas; jogo da memória; leitura e discussão de noticiários; descrição de objetos e lugares.

E o terceiro momento era reservado para a escoIha das atividades da próxima semana, levando em consideração a preferência dos participantes. Esse momento tornou-se importante para o conhecimento dos sujeitos.

A princípio, os sujeitos convidados para participarem do estudo foram os pacientes que já vinham sendo atendidos na Clínica-Escola de Fonoaudiologia da Universidade Federal de Pernambuco, e posteriormente pacientes encaminhados do Hospital das Clínicas da UFPE.

$O$ estudo foi realizado com um grupo de seis sujeitos afásicos e cinco não-afásicos. Foram incluídos sujeitos de ambos os sexos, sem restrições do tipo da lesão cerebral e da condição sócio-cultural.

A pesquisa foi realizada no período de agosto de 2007 a julho de 2008, sendo o Grupo de Convivência iniciado em outubro de 2007.

Os diálogos dos afásicos foram coletados, por meio de gravações e filmagens, que contêm os momentos de interação e conversa espontânea sobre temas de interesse comuns aos participantes. Posteriormente esses diálogos foram transcritos com base no sistema padronizado de transcri- 
ção do NURC - Norma Universal de Transcrição da Norma Culta. Os dados coletados foram analisados à luz dos pressupostos da Análise do Discurso de Linha Francesa e confrontados com os dados da revisão bibliográfica.

Os participantes e pesquisadores assinaram um Termo de Consentimento Livre e Esclarecido, em que se explicava os objetivos do trabalho, seus riscos e benefícios; deveres dos pesquisadores de assumir o compromisso de guardar o sigilo dos participantes e o direito desses de autonomia de participação.

Os sujeitos afásicos tiveram a total liberdade de eliminarem os fragmentos discursivos, os quais não queriam divulgar, além disso, tiveram autonomia para cessar as gravações quando o tema discutido fosse de algo que não pretendiam difundir.

A pesquisa foi aprovada pelo Comitê de Ética em Pesquisa envolvendo seres humanos com o número № 349/07.

Não houve definições de variáveis, pois se trata de uma pesquisa qualitativa, em que é direcionada ao longo do seu desenvolvimento; não busca enumerar ou medir eventos e não emprega instrumentos estatísticos.

\section{RESULTADOS}

Para o processo de análise dos sentidos no discurso dos afásicos, foi realizada a descrição dos temas recorrentes encontrados a partir das transcrições dos encontros.

Abaixo segue a descrição dos temas, mais recorrentes, e sua situação de produção, incluindo a atividade realizada no grupo, os sujeitos e a dinâmica do discurso. Essa descrição pode expressar aquilo que faz parte do cotidiano (do social), da cultura e ideologia dos sujeitos.

Os sujeitos afásicos estão representados por suas iniciais em maiúsculas e destacadas em negrito e os sujeitos não-afásicos por suas iniciais em minúsculas e sem destaque:

INCAPACIDADES: Esse tema se refere a todos os momentos em que os sujeitos do grupo mencionaram sobre suas deficiências físicas; suas alterações linguísticas; seus comprometimentos que os impedia de realizar qualquer atividade. Esse tema foi citado e iniciado exclusivamente pelos sujeitos afásicos, tendo prevalecido, em seus discursos, as queixas quanto às alterações linguísticas e de memória. O exemplo abaixo foi retirado de um momento de conversa espontânea.

A.C.: ...eu ia falar que... antigamente eu falava muito bem... e agora eu to oh... ((faz um sinal negativo com as mãos))
A.C. comenta com outro sujeito afásico sobre sua situação, comparando sua fala antes e depois do $A V C$, considerando que agora está ruim.

LEMBRANÇAS E CONHECIMENTOS: EsSe tema foi destacado nas transcrições, se referindo a pergunta e comentários sobre lembranças de fatos ocorridos e conhecimentos sobre diversos assuntos, músicas, filmes, objetos e também sobre pessoas. Observou-se que esse tema foi iniciado na maioria das vezes por não-afásicos, na tentativa de resgatar a memória e desenvolver a linguagem dos afásicos. O trecho abaixo ocorreu durante a atividade com músicas, em que cada participante falava o nome de um cantor e os demais tentavam lembrar suas músicas:

(...)

lu.: ...então... capiba...

J.: ah::: capiba eu sei... até ele e ele se lembra ((aponta para A.C. e A.)) ... eu me lembro também...

li.: ...capiba escreveu música pra quê?...

J.: pra carnaval...

(...)

Esse diálogo entre não-afásicos e afásico e a atividade realizada contribuíram para um engajamento dos afásicos no fluxo conversacional, evitando a prevalência dos turnos pelos não-afásicos.

MEMÓRIAS, ÉPOCAS DA VIDA: Foi um dos temas bastante discutidos durante os encontros, principalmente no início do grupo; iniciado quase que exclusivamente pelos não-afásicos, com o objetivo de conhecer a história de vida dos participantes. $O$ trecho a seguir mostra uma série de perguntas feita a $\mathbf{C}$. durante um encontro, em que se discutiam preferências musicais.

(...)

es.: ...seu C. porque o senhor escolheu essa música? ... normalista.

li.: ...o que lhe lembra essa música?... ((mostra a letra da música)) lembra que época da sua vida?... Onde cantava essa música?...

li.: ...o senhor era novo ...era?...

C.: ...é::: ((balança a cabeça dizendo que sim)) porque... faz muito tempo isso...

(...)

Observa-se uma série de perguntas direcionadas a C. na tentativa de se obter uma resposta que pudesse caracterizar esse sujeito e saber mais sobre sua vida. A recorrência e insistência nesse tema pelos não-afásicos ocorreram com o objetivo de adequar as atividades a sua história, 
cultura e conhecimentos.FAMÍLIA: Esse tema foi inserido pelos afásicos, quando queriam comentar sobre os acontecimentos e realidades vivenciados em sua casa e com sua família, e iniciado por não-afásicos, com o objetivo de conhecer um pouco da dinâmica familiar dos sujeitos afásicos. O trecho abaixo mostra um comentário de A.C. em um dos encontros, em que se discutiam os papéis de cada um em casa.

\section{(...)}

A.C.: ...minha mulher fala que só...

li.: ...mas ela fala porque tem que fazer as coisas pro senhor... ela...

A.C.: ...ela e o filho... o filho ajuda muito... mas (...)

A.C. comenta sua relação com a esposa, cita o filho como uma pessoa que contribui para sua melhora, mas não leva muito em consideração o trabalho da sua esposa.

RELIGIÃO: A religião foi citada por alguns participantes, principalmente pelos sujeitos evangélicos do grupo, que seguem e mostram princípios relacionados à religião. Por existir a heterogeneidade do grupo, os não-afásicos também se referiam à religião, através de perguntas, para saber a posição de cada sujeito diante de algum assunto. Segue um trecho transcrito em que se discutiu o conhecimento de uma música gospel, escolhida por $\mathbf{A}$. durante um encontro. A atividade tinha o objetivo de compartiIhar preferências musicais.

(...)

li.: ... então... num sei se a senhora viu... essa daqui é de crente ((aponta para a letra da música)).

M.A.: ((olha para a letra e balança a cabeça negativamente)).

li.: ... conhece não?...

A.: ... ah?::: ((olha com surpresa como que indagando o fato de M.A. desconhecer a música))

(...)

Nesse trecho pode-se observar a heterogeneidade do grupo, M.A. é católica e A. é evangélico, sendo natural que M.A. não conheça a música, mas $\mathbf{A}$. demonstra uma incompreensão ou uma insatisfação por M.A. não conhecer.

TRABALHO: Trata-se de um tema em que, na maioria das vezes, foi iniciado por não-afásicos para investigar sobre a profissão e as atividades já realizadas pelos sujeitos afásicos. Também foi comentado, pelos afásicos, em outros encontros, sobre os direitos de aposentadoria, tempo de serviço e insatisfação no trabalho. O trecho a seguir mostra o comentário de $\mathbf{J}$. sobre seu primeiro emprego.

(...)

es.: ... e seu J. o seu primeiro emprego?...

J.: ... meu primeiro emprego... meu primeiro emprego foi serviço gerais... era com máquinas máquinas... trator... trabalhava na Eucoma...

\section{(...)}

J. lembra do início da sua atividade profissional e a primeira empresa que começou a trabalhar. Ele é o único participante que ainda não se aposentou e sempre relata sobre seu trabalho e a atividade que realiza.

DOENÇA/AVC: Esse tema foi bastante discutido, principalmente nos primeiros encontros, em que se buscou explicar sobre as causas e consequências da afasia. $O$ assunto foi interessante para os afásicos, pois eles tinham a necessidade de entender as alterações e saber as expectativas para a melhora. Esse tema também se refere a comentários sobre doenças associadas às alterações linguísticas, além de discussão e comparação das dificuldades de cada um, nesses encontros houve bastante interação entre os sujeitos do grupo. A seguir observa-se um trecho sobre o comentário de J. em relação à lesão cerebral, seu comentário ocorreu no momento em que comparava sua produção oral com a de A.C.

J.: ... se ele levar... se alguém aqui pudesse levar... pra um médico que entendesse a cabeça dele... ele tá com tudo pra ser normal... o meu caso... é... se butar aqui... mas... eu me lembro... eu me lembro...

J. refere sobre as condições de produção oral de A.C., que possui boa fluência, considerando que A.C. não possui uma lesão cerebral como ele, mas que apesar dessa lesão, J. se acha capaz também de lembrar das coisas.

\section{DISCUSSÃo}

Diante dos temas levantados pelos sujeitos do grupo de convivência, foi possível verificar uma predominância das iniciativas dos temas pelos nãoafásicos, no entanto os temas sobre incapacidades e doenças/AVC foram de iniciativa exclusiva dos afásicos. Isso pode indicar o quanto os comprometimentos da saúde interferem na vida e valores dos sujeitos, pois esses temas estiveram presentes na maioria dos seus enunciados.

Analisar o discurso de sujeitos afásicos significa observar o uso da linguagem em suas 
determinações concretas, mas somente, ao analisar a relação discursiva, será possível entender o funcionamento dos dois interlocutores, o que fala e o que quer falar ${ }^{9}$.

Ao serem analisados e interpretados os enunciados produzidos pelo grupo de afásicos, procurando buscar os sentidos nas diversas situações discursivas levantadas pelo grupo, considerando que é o sentido será sempre um resultado, um efeito ou, mais especificamente, uma criação. Em outros termos, pensar a dinâmica discursiva enquanto um conjunto de tramas e redes significantes entrelaçadas conduz à proposta de encarar o sentido como algo construído pelo sujeito, e não como uma formação já dada, perdida e à espera de ser revelada ${ }^{10}$.

Nas situações comunicativas, os sujeitos afásicos ou não-afásicos, participam de eventos comunicativos que possibilitam a vivência de situações de uso sociocultural da linguagem, em contextos verbais e não-verbais, na construção de sentidos ${ }^{11}$.

O grupo foi caracterizado pela sua heterogeneidade, o que fez gerar momentos de discussão, resultando em operações colaborativas dos parceiros da interação que constroem os referentes no e pelo discurso. Considerando a concepção de que a língua é heterogênea, opaca, histórica, variável e socialmente construída ${ }^{12}$.

As palavras, expressões ou proposições mudam de sentido segundo as posições mantidas, o que significa que os enunciados tomam seu sentido em referência a suas posições, isto é, em referência às formações ideológicas nas quais essas posições se inscrevem ${ }^{13}$.

É pelas escolhas que os indivíduos fazem, no processo constitutivo da referenciação, que a argumentação e os encadeamentos argumentativos são possíveis ${ }^{14}$.

Na situação interativa, o sujeito lida com o material linguístico que tem a sua disposição, fazendo escolhas importantes para concretizar a sua proposta de sentido. É com base no exposto que a análise de atividades referenciais pode mostrar como os sujeitos afásicos trabalham a relação linguagem - mundo ${ }^{15}$.

Com a apresentação dos temas recorrentes encontrados no grupo de convivência de afásicos, tentou-se realizar as interpretações dos seus discursos, a fim de desvendar ou atribuir sentidos em seus dizeres. Os sentidos nem sempre estiveram evidenciados e também não foram únicos, sofreram variações, adequando-se aos aspectos sociais, culturais, históricos e ideológicos de cada sujeito.

Assim, esse estudo é passível de diversas formas de interpretação, como também de transformações e mudanças, necessitando sempre de dados a serem acrescentados, complementados e/ou modificados, para que haja sempre a produção de efeitos de sentidos entre os interlocutores.

\section{CONCLUSÃO}

Por meio das transcrições, foi possível encontrar os temas comuns e recorrentes ao discurso de afásicos participantes do Grupo de Convivência, que foram: incapacidades; lembranças e conhecimentos; memórias e épocas da vida; família; religião; trabalho e doenças/AVC. Os temas de maior prevalência e iniciados exclusivamente pelos afásicos foram sobre as incapacidades, doenças/AVC, principalmente sobre as alterações linguísticas.

Verificou-se que o discurso dos afásicos, independente das alterações que possua, está impregnado de sentidos verdadeiros, que se produzem em decorrência da interação social entre os interlocutores, que são sujeitos ativos nessa troca de informações e constituídos de ideologia e história.

A partir dessa reflexão e com base no analisado nesse estudo, destaca-se a necessidade do conhecimento contextual nas atividades dialógicas que envolvem os processos de interpretação e referenciação, garantindo, desta forma, a coerência no momento de atribuir e analisar os sentidos, isso implica conhecer a realidade do outro, pois sem esse conhecimento as interpretações se tornam arbitrárias, sendo assim algo mutável, visto que cada sujeito interpreta de acordo com sua visão de realidade.

\section{AGRADECIMETOS}

Aos meus pais, Sebastião Soares e Ilza de Andrade, pelo amor incondicional, por tudo que sempre fizeram por mim, pelo apoio e pelo incentivo ao estudo;

À Prof ${ }^{\text {. }}$. Dra. Maria Lúcia Gurgel da Costa, pela orientação e pelo estímulo na realização deste trabalho;

Às amigas Ester Feijó e Lívia Luz, pelo apoio, pela amizade, pela ajuda nas transcrições;

Aos participantes afásicos e não-afásicos desta pesquisa, pelo muito que me ensinaram com seus relatos de vida e formas de expressão;

Às professoras, que contribuíram de forma direta ou indireta para a efetivação desse estudo, Vanessa Lima, Marília Macêdo e Ana Carla Vogeley.

À Propesq/UFPE pelo seu apoio na pesquisa. 


\begin{abstract}
Purpose: to analyze the discursive meanings observed in the speech of aphasic subjects in a coexistence group. Methods: the study was conducted at the Speech Therapy department, from Universidade Federal de Pernambuco, where the aphasic coexistence group was formed, constituting by six aphasic subjects \& five non - aphasic. For developing this study's activities, the discussions were recorded and later transcribed, according to the standardized system: NURC (Universal Standard of Transcription), and then we performed the analysis. Results: through the transcripts, it was possible to find the common and the recurring themes of the aphasic speech. They were: disability; memories and knowledge, memories and life phases, family, religion, labor and disease/VEA (Vascular Encephalic Accident). The most common themes initiated by the aphasic subjects were about disabilities, diseases and VEA causes, especially about the linguistic changes. It was found that these subjects' speech, regardless of the changes and problems that they have or have had, is full of real meanings, which are produced as a result of the interaction between the social partners, who are active subjects, on this information exchange, and who are constructed by and ideology and a history. Conclusion: we can see that, even having a reduced or limited speech, the aphasic subjects had behaviors and attempts or efforts to interact with the others, building meaning processes.
\end{abstract}

KEYWORDS: Aphasia; Speech; Language

\section{REFERÊNCIAS}

1. Silva RC. O estatuto da repetição nas afasias. Anais do Seta. 2007; (1):455-61.

2. Fonseca SC. Lesão x sintoma: uma questão sobre a causalidade. Doc Est Linguist Teor Apl. 1998; 14(2):455-66.

3. Macedo HO. Os gêneros textuais escritos e as afasias: o continuum. Oralidade e escrita em evidência [dissertação]. Campinas (SP): Universidade Estadual de Campinas; 2005. 227p.

4. Morato EM. Neurolinguística. In: Mussalin F, Bentes AC, organizador. Introdução à linguística: domínios e fronteiras. São Paulo: Cortez; 2000. p. 143-70.

5. Caregnato RCA, Mutti R. Pesquisa qualitativa: análise de discurso versus análise de conteúdo. Texto Contexto Enferm. 2006; 15(4):679-84.

DOI: 10.1590/S1516-18462009005000050

RECEBIDO EM: 06/04/2009

ACEITO EM: 28/07/2009

Endereço para correspondência:

Aluísia Guerra Albuquerque

Rua Padre Champagnat, CDU/Várzea, 139 ap. 201

Recife - PE

CEP: $50740-320$

E-mail: guerraalu@yahoo.com.br
6. Pinto RCN. Uma reinterpretação do conceito de grau de severidade a partir de uma concepção enunciativo-discursiva de linguagem e dos relatos dos sujeitos afásicos sobre suas dificuldades. Estud Linguíst. 2006; 35:1730-5.

7. Viscardi JM. O estatuto neurolinguístico do automatismo. Rev Cursos de Pós-Graduação. 2006; 11:565-78.

8. Martins ACS. Linguagem, subjetividade e história; a contribuição de Michel Pêcheux para a constituição da análise de discurso. Unimontes Cient. 2004; 6(1):163-9.

9. Freire MR. Análise da afasia sob uma perspectiva discursiva. In: Passos MC. Fonoaudiologia: recriando seus sentidos. São Paulo: Plexus; 1996. $159 \mathrm{p}$.

10. Salztrager R. Das fantasias vazias ao referencial discursivo. Agora. 2008; 11(1):53-65.

11. Sampaio NFS. Um enfoque etnolinguístico da afasia: o centro de convivência de afásicos (Unicamp) como uma comunidade de fala. Rev Cursos de Pós-Graduação. 2007; 12:271-9.

12. Reisdorfer IMS. Produção de parafasias lexicais e semânticas: reflexão a partir dos estudos sobre referenciação. Estud Linguíst. 2006; 35:941-9.

13. Pêcheux M. O discurso: estrutura ou acontecimento. São Paulo: Cortez; 1990. 68p.

14. Tavares ES. A competência argumentativa de pessoas afásicas. Estud Linguíst. 2006; 35:677-84. 15. Bassi E. A construção do sentido em práticas referenciais de afásicos. Estud Linguíst. 2006; 35:710-7. 